\title{
A simple assessment of physical activity is associated with obesity and motor fitness in pre-school children
}

\author{
Otmar Bayer ${ }^{1, *}$, Gabriele Bolte ${ }^{2}$, Gabriele Morlock ${ }^{2}$, Simon Rückinger ${ }^{1}$ and \\ Rüdiger von Kries ${ }^{1}$ for the GME-Study Group \\ 'Institute for Social Paediatrics and Adolescent Medicine, Ludwig-Maximilians University, Heiglhofstraße 63, \\ D-81377 Munich, Germany: ${ }^{2}$ Department of Environmental Health, Bavarian Health and Food Safety Authority, \\ Oberschleißheim, Germany
}

Submitted 15 April 2008: Accepted 18 August 2008: First published online 30 0ctober 2008

\begin{abstract}
Objective: Physical activity is an important determinant of energy balance. However, its impact on overweight/obesity has proved difficult to measure in pre-school children and few studies have found significant associations. A set of simple questions was used to distinguish pre-school children with high and low physical activity, and the association of this classification with childhood overweight/obesity and performance in an established motor test was investigated. Design: Survey, cross-sectional.

Setting and subjects: Weight and height were measured in 12556 children taking part in the obligatory school entrance health examination 2004-5 and 2005-6 in three urban and three rural Bavarian regions. Their parents were asked to answer a questionnaire with a set of questions on physical activity.

Results: The mean age of the children evaluated was 5.78 (SD 0.43) years, 6535 $(52 \cdot 1 \%)$ were boys. Physically active children were less likely to be overweight $(\mathrm{OR}=0 \cdot 786,95 \% \mathrm{CI} 0 \cdot 687,0 \cdot 898)$ or obese (OR $=0 \cdot 655,95 \% \mathrm{CI} 0 \cdot 506,0 \cdot 849)$ and achieved $6 \cdot 7(95 \%$ CI $5 \cdot 8,7 \cdot 7) \%$ more jumps per $30 \mathrm{~s}$ than less active children in a motor test, adjusted for a number of potentially confounding variables.

Conclusions: Classification of pre-school children as physically active or not, based on a small set of questions, revealed significant associations with overweight/obesity and a motor test. Once further validated, this classification might provide a valuable tool to assess the impact of physical activity on the risk of childhood overweight and obesity.
\end{abstract}

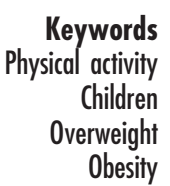

There is little doubt that lack of physical activity in children constitutes a risk factor for childhood overweight/ obesity $^{(1,2)}$. Indeed, there are plenty of studies reporting a positive correlation between hours of watching television (TV) and childhood overweight and obesity ${ }^{(3-5)}$. The number of hours spent in front of the TV set, however, reflects physical inactivity rather than physical activity. Physical activity, an important determinant of energy balance and therefore likely to influence obesity risk, is promoted in many prevention programmes but was only rarely measured on an individual level in the evaluation of these programmes. Several studies attempting to measure physical activity in children failed to show a significant association with overweight/obesity ${ }^{(6-8)}$. This situation may be due to difficulties in measurement (especially in pre-school children $)^{(9)}$ that arise even when technical equipment (accelerometry) is used ${ }^{(10)}$. Only a few studies carried out in this age group make use of methods other than accelerometry ${ }^{(11-13)}$.
In the present study, we report on a simple approach to assess physical activity in pre-school children based on a set of questions in parental questionnaires to classify children as physically active or not. The primary objective of the study was to test whether this classification was associated with childhood overweight/obesity. The secondary objective was to assess whether this classification was also correlated with the results of a simple motor test.

\section{Methods}

\section{Study population}

The study was conducted within the framework of the first and second survey of the health monitoring units in Bavaria (GME, Gesundheits-Monitoring-Einheiten) ${ }^{(14)}$. GME, established in 2004, is supported by the Bavarian State Ministry of the Environment, Public Health and Consumer Protection and is managed by the Bavarian 
Health and Food Safety Authority. Its aims are: (i) the epidemiological surveillance of health and environmental factors with special emphasis on children; (ii) the prompt provision of results to political leaders and decision makers; and (iii) the testing and evaluation of intervention and prevention strategies in cooperation with external research partners. To facilitate the last aim a modular approach is employed. The six regions covered are selected in order to get data representative for Bavaria. The study was approved by the ethics committee of the Bavarian medical council (BLÄK, Bayerische Landesärztekammer). All participating parents gave their written consent. In three urban and three rural Bavarian regions, 8127 and 8558 children taking part in the obligatory school entrance health examination in 2004-5 and 2005-6, respectively, were invited to participate.

\section{Measurements}

Height and weight were measured using standard stadiometers and calibrated scales (usually digital) by trained staff of the local health authority, a motor test was conducted and questionnaires were handed out to parents. Variables relevant to the present study are defined as follows.

1. Overweight/obesity: age- and sex-specific BMI cut-off values were used to classify children as overweight or obese according to Cole's reference system ${ }^{(15)}$.

2. Side-to-side jumps (SHH): the number of jumps over a bar a child can perform within $15 \mathrm{~s}$. The child should jump and land with both feet simultaneously. The numbers of two runs were added up. This test is one item of the Karlsruher-Motorik-Screening ${ }^{(16)}$, a fouritem screener designed for pre-school children to assess physical fitness in terms of strength, coordination and motility. After a pilot phase of 3 years, norm values were calculated on the basis of a sample consisting of 1288 children.

\section{Physical activity (from parent questionnaire)}

Children's activities such as 'climbing', 'playing with a ball', 'playing tag', 'cycling using a bicycle or kickboard' and 'skating' were listed. Parents were asked to rate the frequency of their child's taking part in these activities as 'never', 'less than once per week', '1-2 times per week', '3-6 times per week', 'every day' or 'don't know'. The following cut-off points were chosen based on the frequency distribution of answers in order to divide them into two groups of roughly equal size: (i) climbing, playing with a ball and playing tag were rated as 0 (= rarely) if reported as less than 1-2 times per week, otherwise as 1 (=frequently); (ii) cycling was rated as 0 (= rarely) if reported as less than 3-6 times per week, otherwise as 1 (=frequently); and (iii) skating was rated as 0 (= rarely) if reported as never, otherwise as 1 (=frequently). Out of these dichotomized answers the variable physical activity was compiled and set to 1 (=yes) if at least three of the above activities were rated as frequent. Conversely, if at least three of the five answers were rated as not frequent, the variable was set to $0(=$ no).

Further questions on how the child usually goes to kindergarten, to friends, to the playground, etc. (on foot, by bicycle, by car, etc.), whether there is free space to play outside nearby and TV/computer consumption were asked and dichotomized. Classification as 'rare TV watching' required answers of $<1$ and $3 \mathrm{~h}$ of TV/ computer use per day during the week and weekend, respectively, and no TV set in the child's bedroom.

Parental education (rated as high if at least one of the parents had passed the secondary school qualification examination after 10 years ('Realschulabschluss') or had a higher level of education), parental BMI, German nationality, premature birth and complications after birth were recorded as potential confounders. Parental BMI was calculated from reported weight and height of the father; if not available, of the mother. We chose this approach because paternal BMI has a slightly stronger effect on children's weight status and including both parents' BMI would have led to considerably more missing values.

\section{Statistical analysis}

Statistics were computed in the SAS statistical software package version 9.1 (SAS Institute, Cary, NC, USA). For proportions, exact (binomial) confidence intervals are given. Multivariate logistic regression analysis in conjunction with a backward elimination algorithm (at $\alpha=0 \cdot 05$ ) was used to model odds ratios for overweight/ obesity; Poisson regression was applied to model the multiple of the number of side-to-side jumps in the exposed compared with the non-exposed group.

\section{Results}

The proportion of completed questionnaires was $78 \%$ and $73 \%$ in the first and second survey, respectively, yielding 12556 informative participants available for further analysis. For 12199 (97.2\%) of these, weight, height and gender were reported allowing for classification of overweight or obesity. Measurements of the outcome $\mathrm{SHH}$ were available for 10696 children (94.7\%, smaller denominator, since $\mathrm{SHH}$ was omitted in the Munich region for the second survey). Population characteristics are presented in Table 1 . Boys were rated as physically active significantly more frequently $(41 \cdot 2 \%)$ than girls $(35 \cdot 6 \%)$.

The prevalences of overweight and obesity were lower in children for whom high physical activity was reported. Table 2 shows the prevalences of overweight and obesity by other variables which possibly influence BMI. All variables that were significant in bivariate analysis entered the first multivariate logistic regression model. The final model revealed adjusted effects for physical activity on 
overweight and obesity (Table 3) with almost identical OR compared with the bivariate analysis (bivariate OR of 0.803 and 0.672 for overweight and obesity, respectively).

As shown in Table 4, children reported as being physically active performed significantly more side-to-side jumps than those reported as not being physically active. Other explanatory variables showing significant associations with $\mathrm{SHH}$ in bivariate analysis were 'sex', 'free space to play outside', 'physically active', 'high parental education', 'German nationality', 'premature birth' and 'complications within 4 weeks after birth'. The highest impact on $\mathrm{SHH}$ was found for reported physical activity. All significant variables from the bivariate analysis were included in the Poisson regression model (Table 5). The obtained effect estimate for physical activity fitted very well with the difference seen in bivariate analysis. Since there were also considerable differences in SHH between

Table 1 Characteristics of the study population: subset of children taking part in the obligatory school entrance health examination in 2004-5 and 2005-6, Bavaria, Germany

\begin{tabular}{lcc}
\hline Variable & Mean or $n$ & sD or \% \\
\hline Age (years) & $5 \cdot 78$ & $0 \cdot 43$ \\
Male (\%) & 6535 & $52 \cdot 1$ \\
German nationality (\%) & 11438 & $91 \cdot 5$ \\
High parental education (\%) & 8462 & $70 \cdot 6$ \\
Parental BMl (kg/m ${ }^{2}$ ) & $25 \cdot 70$ & $3 \cdot 53$ \\
Overweight (\%) & 1744 & $14 \cdot 3$ \\
Obese (\%) & 479 & $3 \cdot 9$ \\
Physically active (\%) & 4292 & $38 \cdot 8$ \\
\hline
\end{tabular}

regions (data not shown), these were further added to the model. The variable 'free space to play outside', which was only marginally significant in bivariate analysis $(P=0.0592$ using the non-parametric Wilcoxon-MannWhitney test), was removed $(P=0.2736$ in multivariate analysis), resulting in virtually no change of the other effect estimates.

\section{Discussion}

Data collected in pre-school children in three urban and three rural Bavarian regions revealed that children with high physical activity assessed in a parental questionnaire showed a lower prevalence of overweight and obesity and better results in motor testing.

Energy expenditure and therefore physical activity plays a crucial role for the development of overweight. This might be particularly relevant for pre-school children, who show a higher level of physical activity compared with other age groups ${ }^{(17)}$. Surprisingly, there are few studies on the interdependencies of physical activity in pre-school children and obesity. Additionally, these studies have yielded conflicting results with only a few reporting significant associations ${ }^{(18)}$. This might be due to the different methods of and limitations in the assessment of physical activity applied, rather than to a true absence of effects ${ }^{(3,6,9,19,20)}$. In contrast, a significant, at least moderate association of high physical activity as defined

Table 2 Prevalences of overweight and obesity by reported physical activity and other variables: subset of children taking part in the obligatory school entrance health examination in 2004-5 and 2005-6, Bavaria, Germany

\begin{tabular}{|c|c|c|c|c|c|c|c|c|c|}
\hline \multirow[b]{3}{*}{ Explanatory variable } & \multirow[b]{3}{*}{$n$} & \multicolumn{4}{|c|}{ Overweight } & \multicolumn{4}{|c|}{ Obesity } \\
\hline & & \multicolumn{2}{|c|}{ Exposed } & \multicolumn{2}{|c|}{ Not exposed } & \multicolumn{2}{|c|}{ Exposed } & \multicolumn{2}{|c|}{ Not exposed } \\
\hline & & $\%$ & $95 \% \mathrm{Cl}$ & $\%$ & $95 \% \mathrm{Cl}$ & $\%$ & $95 \% \mathrm{Cl}$ & $\%$ & $95 \% \mathrm{Cl}$ \\
\hline Free space to play outside & 12032 & $14 \cdot 1$ & $13 \cdot 5,14 \cdot 7$ & $17 \cdot 0$ & $14 \cdot 4,19 \cdot 8$ & $3 \cdot 8$ & $3 \cdot 5,4 \cdot 2$ & $5 \cdot 3$ & $3 \cdot 8,7 \cdot 1$ \\
\hline Physically active & 10769 & $12 \cdot 5$ & $11 \cdot 5,13 \cdot 6$ & $15 \cdot 1$ & $14 \cdot 2,16 \cdot 0$ & 3.0 & $2 \cdot 5,3 \cdot 6$ & $4 \cdot 4$ & $4 \cdot 0,5 \cdot 0$ \\
\hline Walking or cycling to kindergarten/friends & 8984 & $14 \cdot 5$ & $13 \cdot 7,15 \cdot 3$ & $14 \cdot 2$ & $12 \cdot 7,15 \cdot 9$ & $4 \cdot 3$ & $3 \cdot 8,4 \cdot 8$ & $3 \cdot 1$ & $2 \cdot 4,4 \cdot 0$ \\
\hline Rare television watching & 10831 & $11 \cdot 2$ & $10 \cdot 4,12 \cdot 0$ & $17 \cdot 5$ & $16 \cdot 4,18 \cdot 7$ & $2 \cdot 2$ & $1 \cdot 9,2 \cdot 6$ & $5 \cdot 7$ & $5 \cdot 1,6 \cdot 4$ \\
\hline High parental education & 11662 & $12 \cdot 0$ & $11 \cdot 3,12 \cdot 7$ & $19 \cdot 2$ & $17 \cdot 9,20 \cdot 5$ & $2 \cdot 8$ & $2 \cdot 5,3 \cdot 2$ & $6 \cdot 0$ & $5 \cdot 2,6 \cdot 8$ \\
\hline German nationality & 12153 & $13 \cdot 4$ & $12 \cdot 7,14 \cdot 0$ & $23 \cdot 8$ & $21 \cdot 3,26 \cdot 6$ & 3.5 & $3 \cdot 2,3 \cdot 9$ & $8 \cdot 3$ & $6 \cdot 7,10 \cdot 1$ \\
\hline Premature birth & 12019 & $10 \cdot 9$ & $8 \cdot 9,13 \cdot 1$ & $14 \cdot 6$ & $13 \cdot 9,15 \cdot 2$ & $2 \cdot 6$ & $1 \cdot 6,3 \cdot 8$ & $4 \cdot 1$ & $3 \cdot 7,4 \cdot 4$ \\
\hline Complications within 4 weeks after birth & 11987 & $13 \cdot 3$ & $11 \cdot 3,15 \cdot 6$ & $14 \cdot 2$ & $13 \cdot 6,14 \cdot 9$ & $3 \cdot 4$ & $2 \cdot 4,4 \cdot 7$ & 3.9 & $3 \cdot 6,4 \cdot 3$ \\
\hline
\end{tabular}

Significant differences are typeset in bold face.

Table 3 Effect estimates* on overweight and obesity from multivariate logistic regression analysis with $P$ values from type III analysis ( $n$ 8712): subset of children taking part in the obligatory school entrance health examination in 2004-5 and 2005-6, Bavaria, Germany

\begin{tabular}{|c|c|c|c|c|c|c|}
\hline \multirow[b]{2}{*}{ Effect } & \multicolumn{3}{|c|}{ Overweight } & \multicolumn{3}{|c|}{ Obesity } \\
\hline & OR & $95 \% \mathrm{Cl}$ & $P$ value & OR & $95 \% \mathrm{Cl}$ & $P$ value \\
\hline Physically active & 0.786 & $0.687,0.898$ & 0.0004 & 0.655 & $0.506,0.849$ & 0.0014 \\
\hline German nationality & 0.642 & $0.509,0.809$ & 0.0002 & 0.601 & $0.410,0.881$ & 0.0091 \\
\hline Parental BMI & $1 \cdot 131$ & $1 \cdot 112,1 \cdot 150$ & $<0.0001$ & $1 \cdot 170$ & $1 \cdot 139,1 \cdot 202$ & $<0.0001$ \\
\hline Region & & & 0.0006 & & & 0.0038 \\
\hline High parental education & 0.645 & $0.562,0.740$ & $<0.0001$ & 0.568 & $0.444,0.726$ & $<0.0001$ \\
\hline Rare television watching & 0.749 & $0.657,0.855$ & $<0.0001$ & 0.518 & $0.402,0.667$ & $<0.0001$ \\
\hline
\end{tabular}

${ }^{*}$ Adjusted for all other explanatory variables in the table. 
Table 4 Results of motor testing by different explanatory variables: subset of children taking part in the obligatory school entrance health examination in 2004-5 and 2005-6, Bavaria, Germany

\begin{tabular}{|c|c|c|c|c|c|}
\hline \multirow[b]{3}{*}{ Explanatory variable } & \multirow[b]{3}{*}{$n$} & \multicolumn{4}{|c|}{ Side-to-side jumps } \\
\hline & & \multicolumn{2}{|c|}{ Exposed } & \multicolumn{2}{|c|}{ Not exposed } \\
\hline & & Number performed & $95 \% \mathrm{Cl}$ & Number performed & $95 \% \mathrm{Cl}$ \\
\hline Female sex & 10696 & $23 \cdot 4$ & $23 \cdot 2,23 \cdot 6$ & $22 \cdot 4$ & $22 \cdot 2,22 \cdot 6$ \\
\hline Free space to play outside & 10564 & $22 \cdot 9$ & $22 \cdot 8,23 \cdot 1$ & $22 \cdot 3$ & $21 \cdot 8,22 \cdot 9$ \\
\hline Physically active & 9449 & $23 \cdot 9$ & $23 \cdot 7,24 \cdot 1$ & $22 \cdot 4$ & $22 \cdot 2,22 \cdot 6$ \\
\hline Walking or cycling to kindergarten/friends & 7809 & $22 \cdot 8$ & $22 \cdot 7,23 \cdot 0$ & $23 \cdot 0$ & $22 \cdot 7,23 \cdot 4$ \\
\hline Rare television watching & 9530 & $23 \cdot 0$ & $22 \cdot 8,23 \cdot 2$ & $22 \cdot 9$ & $22 \cdot 7,23 \cdot 1$ \\
\hline High parental education & 10222 & $23 \cdot 2$ & $23 \cdot 1,23 \cdot 4$ & $22 \cdot 4$ & $22 \cdot 1,22 \cdot 6$ \\
\hline German nationality & 10652 & $23 \cdot 0$ & $22 \cdot 9,23 \cdot 1$ & $21 \cdot 7$ & $21 \cdot 2,22 \cdot 2$ \\
\hline Premature birth & 10546 & $21 \cdot 8$ & $21 \cdot 3,22 \cdot 4$ & $23 \cdot 0$ & $22 \cdot 8,23 \cdot 1$ \\
\hline Complications within 4 weeks after birth & 10502 & $21 \cdot 6$ & $21 \cdot 1,22 \cdot 1$ & $23 \cdot 0$ & $22 \cdot 9,23 \cdot 2$ \\
\hline
\end{tabular}

Significant differences are typeset in bold face.

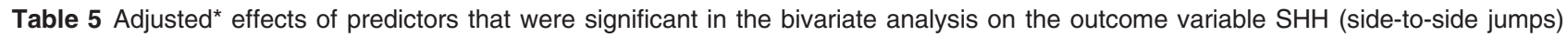
( $n$ 8403): subset of children taking part in the obligatory school entrance health examination in 2004-5 and 2005-6, Bavaria, Germany

\begin{tabular}{lcrr}
\hline & Factort & $95 \% \mathrm{Cl}$ & $P$ value \\
\hline Physically active & 1.070 & $1.060,1.079$ & $<0 \cdot 0001$ \\
Female sex & 1.046 & $1.037,1.055$ & $<0.0001$ \\
Region & & & $<0.0001$ \\
High parental education & 1.039 & $1.029,1.049$ & $<0.0001$ \\
German nationality & 1.013 & $0.993,1.032$ & $0 \cdot 1991$ \\
Premature birth & 0.982 & $0.964,1.001$ & 0.0568 \\
Complications within 4 weeks after birth & 0.947 & $0.930,0.964$ & $<0.0001$
\end{tabular}

*Adjusted for all other explanatory variables in the table.

tThe factors reflect direction (greater or less than 1) and strength of the effect. The number of jumps for children reported e.g. as physically active has to be multiplied by the factor $1 \cdot 070$, implying that these children achieve $7 \cdot 0 \%$ more jumps on average.

by the proposed classification and childhood overweight/ obesity was observed in the present study. Children with high physical activity also performed significantly better in motor testing. This seems plausible and supports the idea that the questionnaire really measures physical activity, rather than other intermediate or confounding variables finally resulting in a lower overweight prevalence.

The physical activities assessed in the questionnaire may have different energy expenditures. A score defined on the relative contribution of the different physical activities to their energy expenditure would be optimal. Since there are no data as to the energy expenditure of e.g. skating, cycling, etc. in young children, it was not possible to define a score based on equal units of energy expenditure related to the different physical activities. Therefore we chose an approach based on distribution only: to define high and low physical activity regarding specific activities we chose the median as a cut-off point.

Well-known risk factors for childhood obesity - such as TV consumption, parental education, parental BMI and non-German citizenship ${ }^{(21-23)}$ - were confirmed in our data. Adjusting for these potential confounders did not change the estimates for the association between reported physical activity and overweight/obesity or motor testing.

Remarkably, watching TV frequently was not significantly associated with the number of side-to-side jumps whereas a significant association to overweight/obesity was observed. It is hypothesized that watching a lot of TV causes overweight through three mechanisms ${ }^{(4)}$ : (i) displacement of physical activity; (ii) increased energy consumption while watching or caused by the effects of advertising; and (iii) reduced resting metabolism. When controlling for physical activity (i), still other pathways remain. Only the first of the suggested mechanisms, lack of physical activity (i), is likely to exert an effect on motor fitness.

Given the high return rates of the informative questionnaires, selection bias is unlikely. The regions were selected in order to include urban and more rural regions. Regional differences with respect to the number of jumps were adjusted using multivariate analysis.

Since the data were assessed in a cross-sectional study, reverse causation cannot be excluded: overweight or obese children might be less physically active because of their fatness.

Because we report associations to illustrate the validity of an assessment tool, reverse causation is not an issue: regardless of the direction of the causation, a valid assessment tool should find physically less active children who - be it in consequence or as a cause of their low physical activity - are more likely to be overweight. The potential prognostic relevance of high physical activity as defined in the present study needs to be established in prospective studies. 
A limitation to be noted is that the analysis did not take into account the food intake of the participating children. Assessment of dietary habits was not feasible in this large sample collected on a surveillance basis. Since the classification as physically active is based on parental reports the results could be subject to information bias, in particular if the resulting misclassification was differential between over- and normal-weight children. Assuming that parents of overweight children - in knowledge of the beneficial effects of physical activity on overweight over-reported physical activity, the estimates of our study would be biased towards the null. Compared with other studies ascertaining physical activity by one or two questions $^{(11,12)}$ (intervention studies with $n 186$ and 400, respectively) or outdoor playing time as a surrogate marker $^{(13)}$ (validation study, $n$ 250), the set of questions used in the present study is conceptually different by listing children's activities, which might be a useful complementary approach.

The current results can be seen as a successful attempt to demonstrate survey-based physical activity rating being correlated with weight status and a motor test in a large sample. Although the results are promising, validation against other methods is required to recommend this set of questions as an assessment tool in epidemiological research. This is planned in collaboration with an ongoing study involving accelerometry, pedometry, activity diary-keeping and electrocardiography monitoring.

A strength of the proposed approach to assess physical activity in pre-school children is its simplicity and high acceptance by parents: in $88.2 \%$ of the completed questionnaires there were sufficient answers to compile the variable 'physically active'. Other ways to measure regular physical activity require considerable effort (e.g. direct observation of physical activity) ${ }^{(24)}$ or invasive methods (e.g. $\mathrm{V}_{\mathrm{O} 2 \max }$ used to assess physical fitness as a proxy) ${ }^{(25)}$. This simple approach therefore might be a useful tool to assess physical activity in pre-school children in studies on causes of childhood obesity. Further validation against other methods is warranted.

\section{Acknowledgements}

The GME-Study Group comprises members from: the Bavarian Health and Food Safety Authority, Oberschleißheim (Gabriele Bolte, Hermann Fromme, Annette Heißenhuber, Michael Mosetter, Gabriele Morlock, Christine Mitschek, Uta Nennstiel-Ratzel, Manfred Wildner); the Health Authority of the District Office of Bamberg (Winfried Strauch, Wiltrud Doerk, Rosemarie Sittig, Heidi Thamm); the Health Authority of the District Office of Guenzburg (Roland Schmid, Tatjana Friess-Hesse, Gudrun Winter); the Health Authority of the City Ingolstadt (Elisabeth Schneider, Traudl Tontsch, Christine Gampenrieder, Margot Motzet, Gerlinde Woelk); the Department of Health and Environment, City of Munich (Heidi Mayrhofer, Sylvia Kranebitter, Gertraud Rohrhirsch, Brigitte Weise); the Health Authority of the District Office of Schwandorf (Maximilian Kuehnel, Kornelia Baranek, Gitte KochSinger); the Institute of Social Paediatrics and Adolescent Medicine, Ludwig-Maximilians University, Munich (Ruediger von Kries, Ladan Baghi); and the Bavarian State Ministry of the Environment, Public Health and Consumer Protection (Bernhard Liebl).

Funding: O.B. was supported by LMUinnovativ research priority project MCHealth (sub-project I). Data management was supported by the Bavarian State Ministry of the Environment, Public Health and Consumer Protection.

Conflicts of interest: none declared by any of the authors.

Contributorship: O.B. - statistical analysis, conception and writing of the manuscript; G.B. - coordination and data management of the GME health survey, review of the manuscript; G.M. - development of questionnaire items, review of the manuscript; S.R. - consulting on the statistical analysis, review of the manuscript; R.v.K. conceiving the evaluation concept, questionnaire items, writing the manuscript.

\section{References}

1. Moore LL, Nguyen US, Rothman KJ, Cupples LA \& Ellison RC (1995) Preschool physical activity level and change in body fatness in young children. The Framingham Children's Study. Am J Epidemiol 142, 982-988.

2. Must A \& Tybor DJ (2005) Physical activity and sedentary behavior: a review of longitudinal studies of weight and adiposity in youth. Int J Obes (Lond) 29, S84-S96.

3. Mendoza JA, Zimmerman FJ \& Christakis DA (2007) Television viewing, computer use, obesity, and adiposity in US preschool children. Int J Behav Nutr Phys Act $\mathbf{4}, 44$.

4. Robinson TN (2001) Television viewing and childhood obesity. Pediatr Clin North Am 48, 1017-1025.

5. Bryant MJ, Lucove JC, Evenson KR \& Marshall S (2007) Measurement of television viewing in children and adolescents: a systematic review. Obes Rev 8, 197-209.

6. Jiang J, Rosenqvist U, Wang H, Greiner T, Ma Y \& Toschke AM (2006) Risk factors for overweight in 2- to 6-year-old children in Beijing, China. Int J Pediatr Obes 1, 103-108.

7. Ara I, Moreno LA, Leiva MT, Gutin B \& Casajús JA (2007) Adiposity, physical activity, and physical fitness among children from Aragón, Spain. Obesity (Silver Spring) 15, 1918-1924.

8. Aeberli I, Kaspar M \& Zimmermann MB (2007) Dietary intake and physical activity of normal weight and overweight 6 to 14 year old Swiss children. Swiss Med Wkly 137, 424-430.

9. Campbell KJ \& Hesketh KD (2007) Strategies which aim to positively impact on weight, physical activity, diet and sedentary behaviours in children from zero to five years. A systematic review of the literature. Obes Rev $\mathbf{8}, 327-338$.

10. Toschke JA, von Kries R, Rosenfeld E \& Toschke AM (2007) Reliability of physical activity measures from accelerometry among preschoolers in free-living conditions. Clin Nutr 26, 416-420.

11. McGarvey E, Keller A, Forrester M, Williams E, Seward D \& Suttle DE (2004) Feasibility and benefits of a parent-focused 
preschool child obesity intervention. Am J Public Health 94, 1490-1495.

12. Fitzgibbon ML, Stolley MR, Schiffer L, Van Horn L, KauferChristoffel K \& Dyer A (2006) Hip-Hop to Health Jr. for Latino preschool children. Obesity (Silver Spring) 14, 1616-1625.

13. Burdette HL, Whitaker RC \& Daniels SR (2004) Parental report of outdoor playtime as a measure of physical activity in preschool-aged children. Arch Pediatr Adolesc Med 158, 353-357.

14. Bolte G, Heissenhuber A, von Kries R, Liebl B, Zapf A, Wildner M \& Fromme H; GME-Study Group (2007) [Health monitoring units in Bavaria. Concept, aims and thematic focus of the first survey on children's environment and health]. Bundesgesundheitsblatt Gesundheitsforschung Gesundheitsschutz 50, 476-483.

15. Cole TJ, Bellizzi MC, Flegal KM \& Dietz WH (2000) Establishing a standard definition for child overweight and obesity worldwide: international survey. BMJ 320, $1240-1243$.

16. Bös K, Bappert S, Tittlbach S \& Woll A (2004) KarlsruherMotorik-Screening für Kindergartenkinder (KMS 3-6). Sportunterricht 3, 79-87.

17. Sigmund E, De Ste Croix M, Miklánková L \& Frömel K (2007) Physical activity patterns of kindergarten children in comparison to teenagers and young adults. Eur J Public Health 17, 646-651.

18. Jago R, Baranowski T, Baranowski JC, Thompson D \& Greaves KA (2005) BMI from 3-6 y of age is predicted by
TV viewing and physical activity, not diet. Int J Obes (Lond) 29, 557-564.

19. Marshall SJ, Biddle SJH, Gorely T, Cameron N \& Murdey I (2004) Relationships between media use, body fatness and physical activity in children and youth: a meta-analysis. Int J Obes Relat Metab Disord 28, 1238-1246.

20. Connelly JB, Duaso MJ \& Butler G (2007) A systematic review of controlled trials of interventions to prevent childhood obesity and overweight: a realistic synthesis of the evidence. Public Health 121, 510-517.

21. Viswanath K \& Bond K (2007) Social determinants and nutrition: reflections on the role of communication. $J$ Nutr Educ Behav 29, 2 Suppl., S20-S24.

22. Toschke AM, Beyerlein A \& von Kries R (2005) Children at high risk for overweight: a classification and regression trees analysis approach. Obes Res 13, 1270-1274.

23. Lampert T, Mensink GBM, Romahn N \& Woll A (2007) [Physical activity among children and adolescents in Germany. Results of the German Health Interview and Examination Survey for Children and Adolescents (KiGGS)]. Bundesgesundheitsblatt Gesundheitsforschung Gesundheitsschutz 50, 634-642.

24. Goran MI (1998) Measurement issues related to studies of childhood obesity: assessment of body composition, body fat distribution, physical activity, and food intake. Pediatrics 101, 505-518.

25. Nakagaichi M, Lee MS \& Tanaka K (2001) Accuracy of two simple methods for the assessment of health-related physical fitness. Percept Mot Skills 92, 37-49. 